\title{
Bubble Evolution in Ultrasonic Wave-Assisted Underwater Wet FCAW
}

\author{
The interaction of ultrasonic waves with an arc bubble results in \\ changed bubble dynamics and improved process stability
}

J. WANG, Q. SUN, J. TENG, AND J. FENG

\begin{abstract}
Ultrasonic wave-assisted underwater wet welding (UUWW) is a newly developed welding method. The principle of this method is to apply the acoustic radiation force to the arc bubble as an extra retaining force. The dynamic feature of the bubble under an acoustic field was demonstrated and analyzed by visual sensing and welding electrical signals. Comparative experiments indicated that, under the same conditions, the additional ultrasonic wave caused the bubble's motion with a certain angle with respect to the welding torch axis so the welding process was not easily affected by the rising of lateral bubbles. Meanwhile, there was always a relatively large bubble maintained in the weld pool surface. The oscillation of the bubble with small amplitude was observed and no necking was present at the bubble bottom. The measurement results revealed that the exertion of ultrasonic wave resulted in a reduced fluctuation of welding electrical signals and an improvement in the arc burning process. For the variation coefficient, the difference between underwater wet welding and U-UWW became significant with varying experimental groups, the maximum difference of which occurred at Group 4.
\end{abstract}

\section{KEYWORDS}

- Ultrasonic Wave • Underwater Wet Welding

- Bubble Dynamics • Process Stability

- Arc Burning Process

\section{Introduction}

Underwater wet welding (UWW) is predominantly employed in the maintenance and repair of offshore structures due to its advantages, such as cost saving, process simplicity, and better adaptability compared with dry and local dry cavity welding (Refs. 1, 2). In UWW, the welding takes place by formation of a bubble surrounded by the water environment. The bubble atmosphere is determined by the decomposition of the used welding flux and the partial vaporization or ionization of the surrounding water induced by the radiative heat from the welding arc and some amount of joule heating in the weld pool (Ref. 3). Jia et al. found a breakdown of water molecules into $\mathrm{H}_{2}$ or $\mathrm{H}$ atoms under welding temperatures, and they were part of the arc plasma (Ref. 4). Due to the interaction between the bubble and the water environment, the process stability and joint quality of UWW is highly related to bubble dynamics, which is influenced by many factors.

In UWW, arc behavior, metal transfer, and weld pool solidification proceed inside the bubble. However, the bubble presents various dynamic behaviors, including growth, detachment, and burst (Ref. 5). These characteristics of an oscillating bubble play a significant role in the UWW process. Early experimental research on the dynamic bubble effect were reported in the literature. Their study on the topics included the heat loss mechanism (Ref. 6), arc behavior (Ref. 5), metal transfer (Refs. 7, 8), process stability (Ref. 9), and weld pool solidification (Ref. 10). Results demonstrated that the dynamic bubble exerted an adverse effect on the entire welding process, which restricted the improvement of UWW.

Tsai and Masubuchi reported that the heat loss was closely related to the dynamic bubble, and inferred that high heat loss in the weld pool was caused by the interaction between the water environment and the rising bubble (Ref. 10). In addition, more arc heat would be lost if the bubble rose too fast, thereby resulting in the reduction of arc temperature (Ref. 11). Jia et al. analyzed the relationship between the evolving bubble and the arc behavior, and found that arc deviation was affected by the drifting arc cathode, induced by the unstable bubble (Ref. 5). In Refs. 12 and 13, the relationship between the bubble dynamics and the welding electrical signals was also established to reveal the dependence of process stability on bubble dynamics. Further, it was deduced and summarized that the larger volume and lower rising frequency of the bubble could help to stabilize the welding process (Ref. 14).

Additionally, the generation of a brittle microstructure and cold cracking was the result of the rapid cooling rate in the weld metal caused by the oscillation of the rising bubble (Refs. 15-17). The real-time induction heating method (Ref. 18) and temper bead welding technique (Ref. 19) were focused on the mitigation of the detrimental weld properties in UWW, but the effect of bubble oscillation was not consid- 


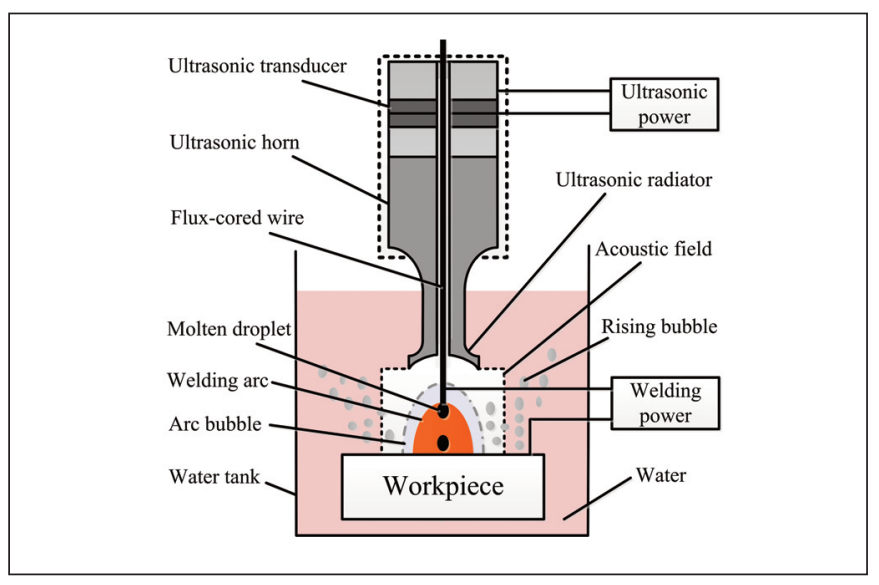

Fig. 1 - Schematic of the ultrasonic wave-assisted underwater wet welding (U-UWW) system.
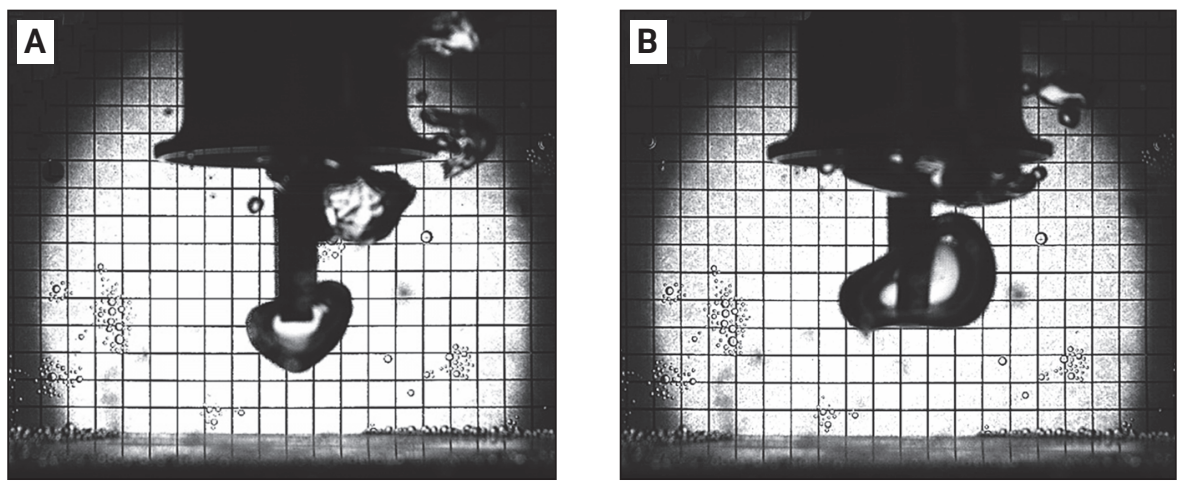

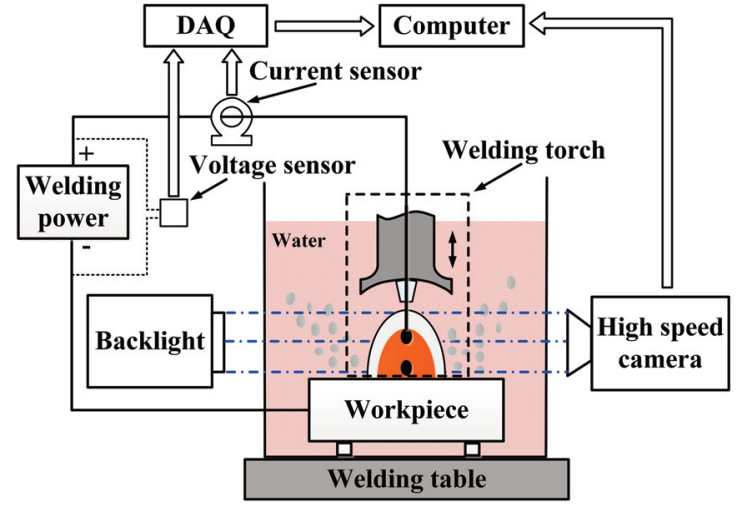

Fig. 2 - Schematic of the real-time monitoring system.

Fig. 3 - Gas bubble motion process in water: A - Gas bubble prior to rising at the tip of the gas tube; B - bubble rising without ultrasonic wave; $C$ - bubble extending downwardly with the ultrasonic wave.

ered. Guo et al. found the molten droplet was repelled and fell outside the weld pool, forming a spatter if bubble oscillation was very violent (Ref. 20). As far as the underwater welding environment was concerned, the hydrostatic pressure (Ref. 21) and water flow (Ref. 22) were crucial factors influencing the bubble dynamics and the resulting process stability. Thus, understanding the mechanism of bubble dynamics is strongly required to suppress these issues and achieve higher weld quality. Furthermore, controlling and getting the stable bubble evolution is still a challenge.

Since bubble dynamics have a crucial effect on the process stability and weld quality, the control technology of the UWW bubble dynamics attracts many researchers' attention. There are a few preceding papers on reasonable control of the bubble through the modification of the UWW process. Two kinds of approaches to achieve bubble control can be described in the literature. By optimizing welding parameters, research has been carried out to demonstrate the conditions of forming a stable bubble (Refs. 13, 14). A better protective effect afforded by the optimized bubble can be achieved. However, this method can only be effective to a certain extent because the arc burning process is also determined by welding parameters. The second approach can be developed on the basis of the active control of the bubble. The local cavity method using a movable chamber (Ref. 23) or utilizing a deep, narrow groove (Ref. 24) was capable of restricting the rise of the bubble, which might contribute to stabilizing the welding process.
Wang et al. developed a mechanical constraint-assisted UWW process, where the bottom surface of the brass cylinder interacted with the bubble, and the latter was controlled for providing a better protective zone (Ref. 25). However, the welding spatter was easily attached on the bottom surface of the constraint device and caused some difficulty in process operation. Hence, any beneficial improvement that produces a controllable and stable bubble is of great significance to support the application of the UWW process.

Ultrasonic wave, characterized by the mechanical effect, acoustic streaming, and the cavitation effect, has the advantages of improving the operation efficiency and technical characteristic in the arc welding process (Refs. 26, 27). Sun et al. applied the ultrasonic vibration in gas tungsten arc welding (GTAW) (Refs. 28, 29). The main body of the ultrasonic system included the ultrasonic transducer and the ultrasonic horn. The acoustic field was formed between the horn and the workpiece. The ultrasonic vibration was imposed on the welding arc, and the latter was compressed (Ref. 29). Fan et al. adapted this method in gas metal arc welding (GMAW), where the nonconsumable tungsten electrode was replaced by a consumable metal electrode (Refs. 30-32). In addition to the compressed arc, under the action of acoustic radiation force, the globular transfer could be changed to the short-circuiting transfer for certain welding conditions (Ref. 33).

A more recent publication by $\mathrm{Wu}$ et al. further adapted ultrasonic vibration in plasma arc welding (PAW) (Ref. 34). The 

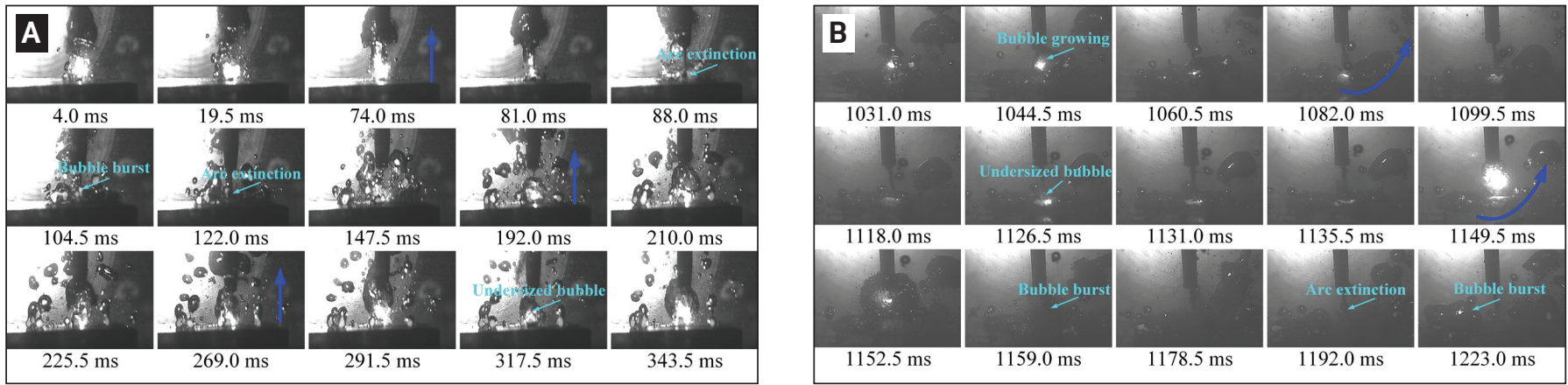

Fig. 4 - The captured bubble dynamic images at Group 1: A - Test Case 1, UWW; B - Test Case 2, U-UWW.

tungsten electrode, mechanically linked with the ultrasonic transducer, vibrated axially and directly transmitted the ultrasound into the plasma arc. With ultrasonic vibration, the plasma arc caused further constriction, and its keyholing capability was enhanced. Therefore, ultrasonic wave-assisted GTAW, GMAW, and PAW produced satisfactory process effectiveness. Nevertheless, a welding electrode of high temperature can affect the physical properties of the ultrasonic vibration unit, possibly weakening the ultrasonic energy (Refs. 35, 36). As a result, forced water cooling is strongly required.

However, most of these investigations of ultrasonic waveassisted arc welding focused on onshore welding. By contrast, UWW has its own characteristics, completely different from onshore welding. The arc burning space of UWW has a particular structure, and the arc behavior, metal transfer, and weld pool solidification proceed inside the bubble (Refs. $5,37)$. Due to the presence of the bubble, it is impossible to apply ultrasonic wave directly to the arc burning space, as in the cases of GTAW, GMAW, and PAW. Hence, the application of the ultrasonic wave in the UWW process may become a novel research topic. In Ref. 38, the authors proposed a novel welding method, ultrasonic wave-assisted underwater wet welding (U-UWW), for the first time. The experimental results showed the arc stability was enhanced, and the microstructure of the joints was improved, which led to the improvement of weld morphology and mechanical properties.
As an inherent property of wet welding, the bubble dynamics has a key effect on process stability; however, the characteristics of the bubble dynamics in the novel U-UWW process have not been systematically studied.

To achieve the visual observability of the bubble and investigate its evolution characteristics in UWW, the dysprosium lamp technique as backlight support was developed to provide a clear view of the bubble (Ref. 5). The advantage of using this method is that it has excellent image resolution and quality for the bubble. Consequently, the bubble evolution events can be easily detected (Ref. 13). On the other hand, the dynamics of the gas-injected bubble from submerged orifices have been extensively studied (Refs. 39, 40). When ultrasound is imposed on a liquid condition, the gas-injected bubble tends to trap in the acoustic field with various behaviors (Ref. 41). With the action of acoustic radiation force, the motion of the gas-injected bubble is controlled at a certain position (Refs. 42, 43). For the heat-induced bubble with a high expansion rate and large diameter in UWW, how can the addition of ultrasonic waves change the bubble dynamic feature and enhance the process stability? It is a very interesting research topic worthy of attention.

The purpose of this study is to focus on the bubble dynamic feature under an acoustic field for the first time, and reveal the relationship between the welding parameters and the bubble dynamic feature in the novel U-UWW process. By observing

Table 1 - The Welding Conditions Used in Experiments

\begin{tabular}{|c|c|c|c|c|c|}
\hline Group & $\begin{array}{l}\text { Test Case } \\
\text { No. }\end{array}$ & $\begin{array}{l}\text { Wire Feeding Speed } \\
\qquad(\mathrm{m} / \mathrm{min})\end{array}$ & $\begin{array}{l}\text { Arc Voltage } \\
\text { (V) }\end{array}$ & $\begin{array}{l}\text { Welding Speed } \\
\qquad(\mathrm{mm} / \mathrm{s})\end{array}$ & $\begin{array}{l}\text { Ultrasonic } \\
\text { Vibration }\end{array}$ \\
\hline \multirow{2}{*}{1} & 1 & 7.5 & 20 & 2.5 & No \\
\hline & 2 & 7.5 & 20 & 2.5 & Yes \\
\hline \multirow{2}{*}{2} & 3 & 6.0 & 28 & 2.5 & No \\
\hline & 4 & 6.0 & 28 & 2.5 & Yes \\
\hline \multirow{2}{*}{3} & 5 & 9.0 & 32 & 2.5 & No \\
\hline & 6 & 9.0 & 32 & 2.5 & Yes \\
\hline \multirow{2}{*}{4} & 7 & 7.5 & 40 & 2.5 & No \\
\hline & 8 & 7.5 & 40 & 2.5 & Yes \\
\hline 5 & 9 & 9.0 & 38 & 2.5 & No \\
\hline
\end{tabular}



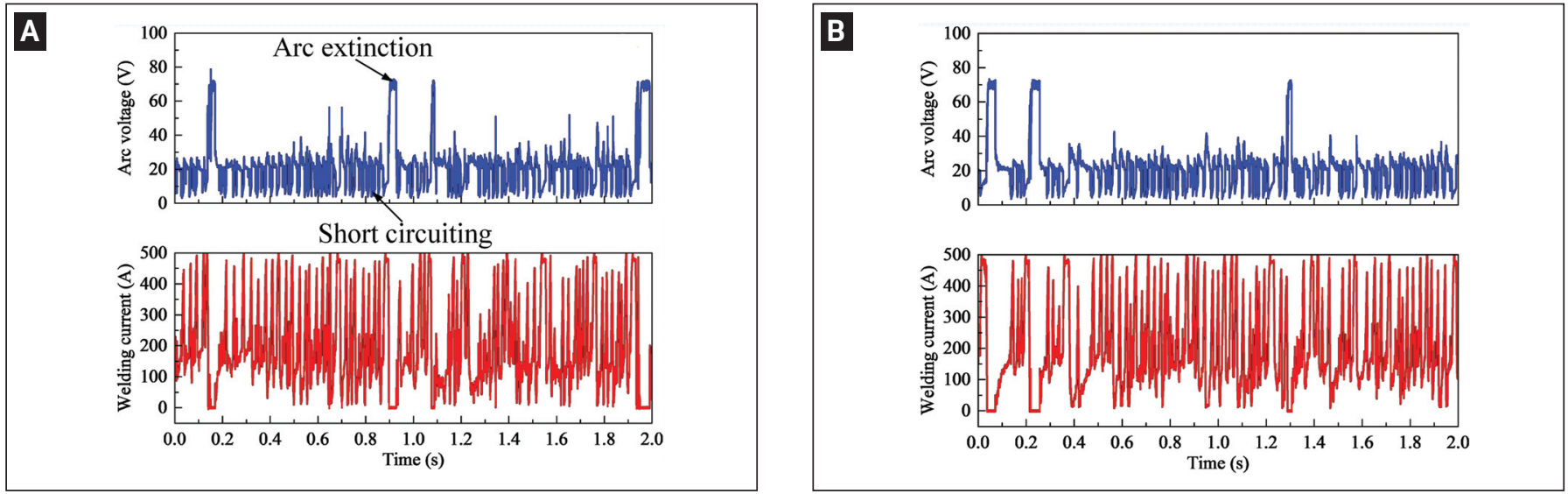

Fig. 5-Arc voltage and welding current waveforms with time at Group 1: A - Test Case 1, UWW; B - Test Case 2, U-UWW.
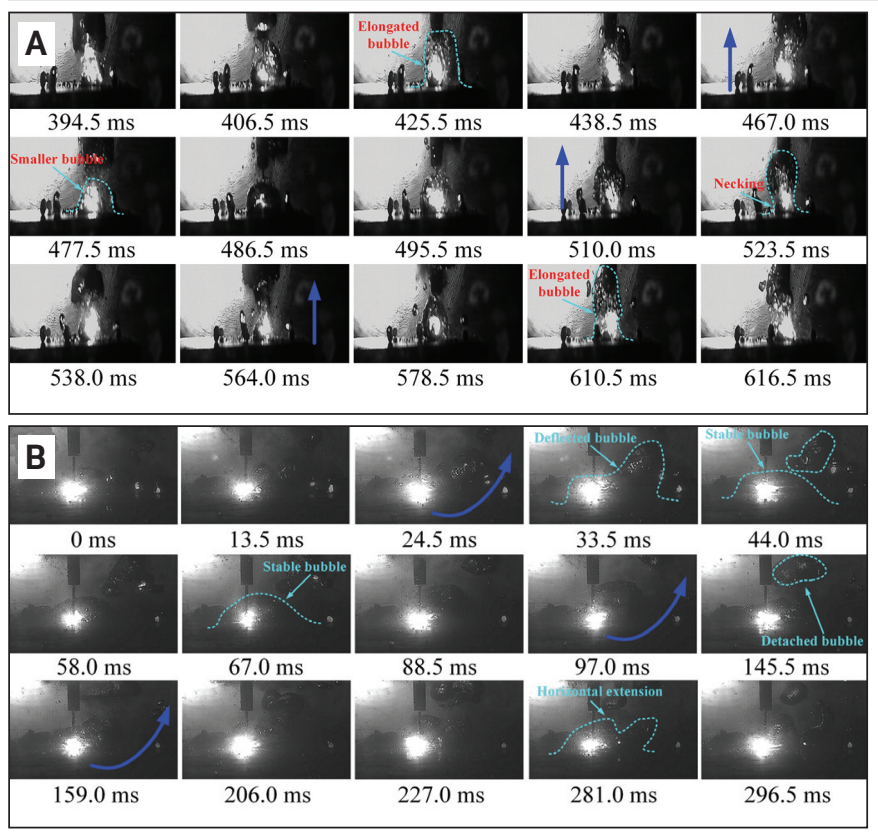

Fig. 6 - The captured bubble dynamic images at Group 2: A - Test Case 3, UWW; B - Test Case 4, U-UWW.

the high-speed imaging in conjunction with the corresponding welding electrical signals, comparative experiments were carried out to specifically discuss how the ultrasonic wave changed the bubble dynamic feature. Furthermore, the influence of the bubble dynamic feature without and with ultrasonic waves on the process stability was also investigated by the authors. The results are helpful for a comprehensive understanding of the U-UWW method.

\section{Experimental Procedures}

\section{Experimental System}

Figure 1 shows the schematic view of an U-UWW system, which included three main parts: ultrasonic radiation system, welding system, and water supply tank. The ultrasonic radiation system consisted of the ultrasound power source, ultrasonic transducer, and ultrasonic horn. The threaded connection was arranged between the transducer and the horn to allow the complete transmission of vibration energy. The piezoelectric material in the transducer generated the mechanical vibration that was amplified by the horn and then radiated out from the ultrasonic radiator in the form of ultrasonic waves. A radiator with a concave construction was designed. Subsequently, the ultrasonic vibration from the radiator was transmitted through water medium and acted on the arc bubble, so the latter's characteristics made an obvious change.

The welding system consisted of the Lincoln Electric ${ }^{\circledR}$ Power Wave ${ }^{\circledR}$ S350 power source, an automatic wire feeder, and a long copper welding torch. During the welding process, the power source was worked in a constant voltage mode with direct current electrode positive condition. The copper welding torch was directed through the central hole drilled through the transducer and the horn, and provided access to the wire feeding. Then the ultrasonic radiation system and the welding system were fixed to the five-axis robotic manipulator.

A water tank of oblong construction was prepared with four glass lateral walls. The distance between the ultrasonic radiator tip and the workpiece surface was $50 \mathrm{~mm}$. Because the bead-on-plate welding experiments were carried out at a water depth of $250 \mathrm{~mm}$, the water surface should be 200 $\mathrm{mm}$ of magnitude higher than the ultrasonic radiator tip. In other words, the ultrasonic radiation system was submerged into the water depth of $200 \mathrm{~mm}$. Thus, the amplified ultrasonic vibration was emitted from the radiator and propagated through the water medium. Finally, the flux-cored wire inside the copper welding torch was ignited with the workpiece for UWW and U-UWW.

\section{Real-Time Monitoring System}

As shown in Fig. 2, the high-speed camera (Olympus iSPEED 3) and the dysprosium lamp, constituting a highspeed imaging system, were placed outside the water tank and remained at constant positions. Opposite to the camera, the dysprosium lamp was placed to provide a background light source. The bubble at the workpiece surface was clearly imaged by using this system with a frame rate of $2000 \mathrm{f} / \mathrm{s}$ to observe its behavior and motion feature when the U-UWW system was established. During the welding process, the workpiece and the water tank traveled at a fixed welding 
A
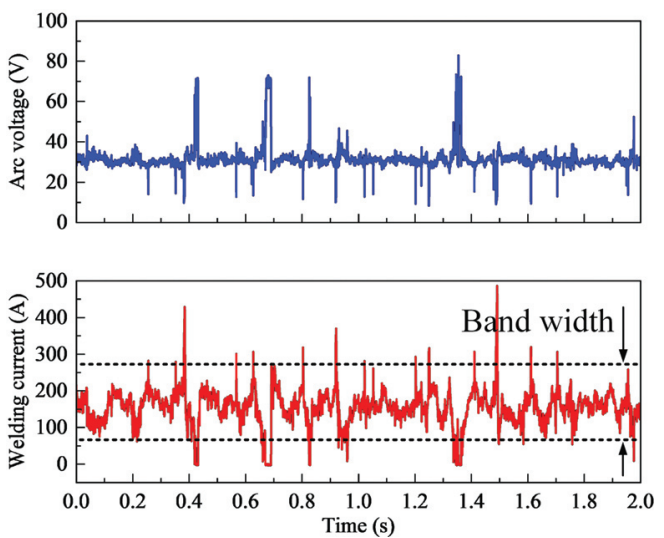

B
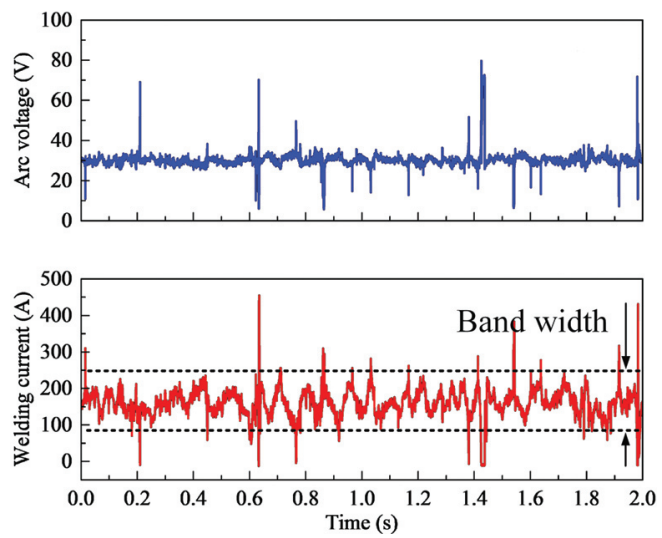

Fig. 7 - Arc voltage and welding current waveforms with time at Group 2: A - Test Case 3, UWW; B - Test Case 4, U-UWW.

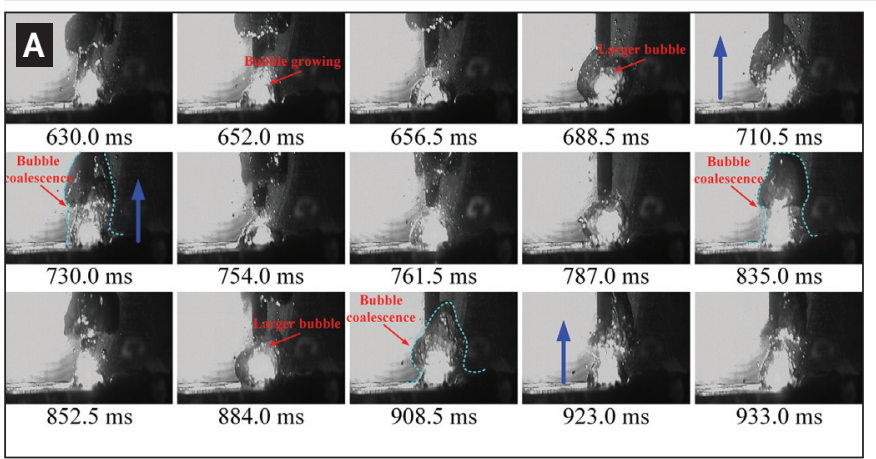

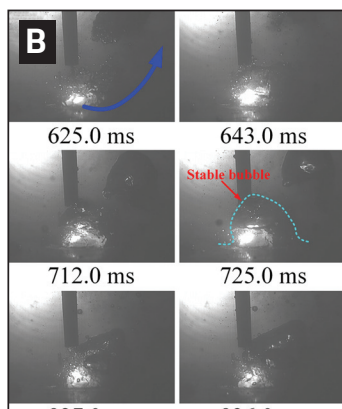

$927.0 \mathrm{~ms}$

$936.0 \mathrm{~ms}$

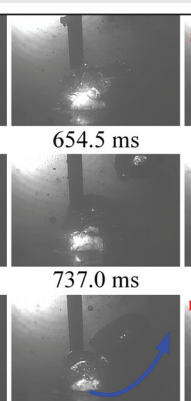

$950.5 \mathrm{~ms}$

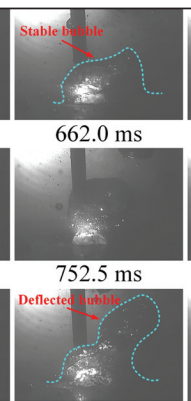

$961.0 \mathrm{~ms}$

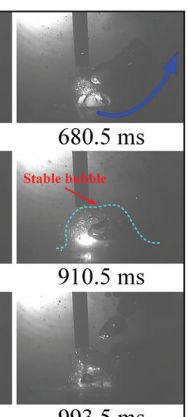

$993.5 \mathrm{~ms}$

Fig. 8 - The captured bubble dynamic images at Group 3: A - Test Case 5, UWW; B - Test Case 6, U-UWW.

speed, while the welding torch and the imaging system were kept stationary.

To characterize the process stability, the welding electrical signals were recorded at a sampling frequency of $10 \mathrm{kHz}$ by using a Hall sensor (current sensor and voltage sensor). The welding current and arc voltage waveforms were digitized by the data acquisition card and processed by the control computer. Note that the high-speed imaging system and welding electrical signals were not synchronized.

\section{Welding Test Conditions}

The bead-on-plate welding tests were carried out on E40 steel plates of $8 \mathrm{~mm}$ thickness. The used welding consumable was a titanium-type slag system, flux-cored wire with $1.2 \mathrm{~mm}$ in diameter. The contact tip-to-workpiece distance was kept at $16 \mathrm{~mm}$. The ultrasonic frequency was $15 \mathrm{kHz}$. In the experiments, the curvature radius of the concave radiator and the distance between the radiator tip and the workpiece surface were controllable parameters for evaluating the efficiency of the ultrasonic wave. However, this is not a primary concern in the study. The concave radiator with a curvature radius of 30 mm was applied.

There are two welding parameters, considered the major parameters, affecting the bubble evolution mode. They included wire feed speed $\left(v_{w}\right)$ and arc voltage $(U)$, and were used to form the parameter vectors $\left\{\mathrm{v}_{\mathrm{w}}, \mathrm{U}\right\}$. The experimental parameters are shown in Table 1.

\section{Experimental Results Theoretical Foundation}

To better reveal the underlying mechanism, a preliminary experiment was conducted to evaluate the effect of the ultrasound in water. The motion of the gas-injected bubble in water was similar to the dynamic process of the arc bubble generated by UWW. The simulation experiment was carried out by a gas tube with the inner diameter of $6 \mathrm{~mm}$. The tip of the tube was placed in the area where the arc bubble existed. The gas bubble motion process was recorded by the high-speed imaging system, as shown in Fig. 3. The instantaneous image of the gas bubble prior to rising is shown in Fig. 3A. During the bubble growth process, there existed an equilibrium condition at the interface between gas bubble, tube tip, and water. As a result, the gas bubble grew steadily at the tip of the tube until it acquired almost its maximum volume.

When increasing to its departure volume, the gas bubble would detach from the tip of the tube either by introducing a small perturbation around the bubble or by a small increase in the gas volume. As shown in Fig. 3B, the gas bubble was directly accelerated along its upward trajectory when the experiment was carried out without the ultrasonic wave. As observed, the gas bubble had a nearly spherical shape with few deformations during the rising process. However, with the ultrasonic waves, the gas bubble migrated downward and its motion trajectory was so different from that without ultrasonic wave. The most obvious feature was the 

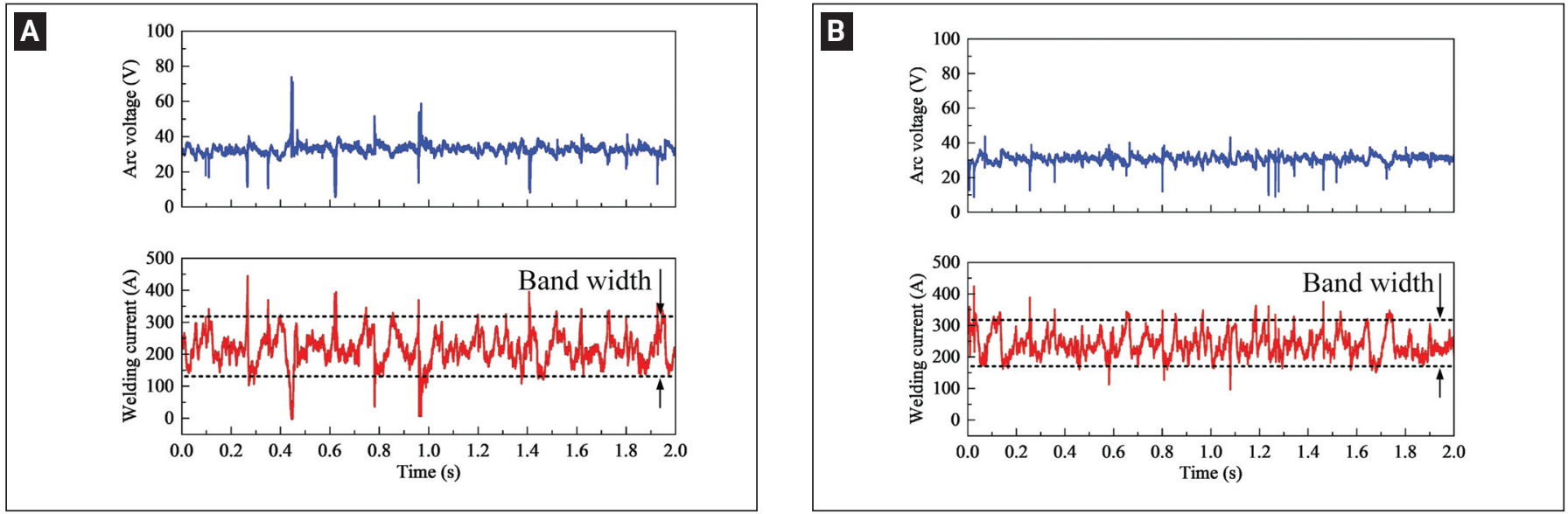

Fig. 9-Arc voltage and welding current waveforms with time at Group 3: A - Test Case 5, UWW; B - Test Case 6, U-UWW.
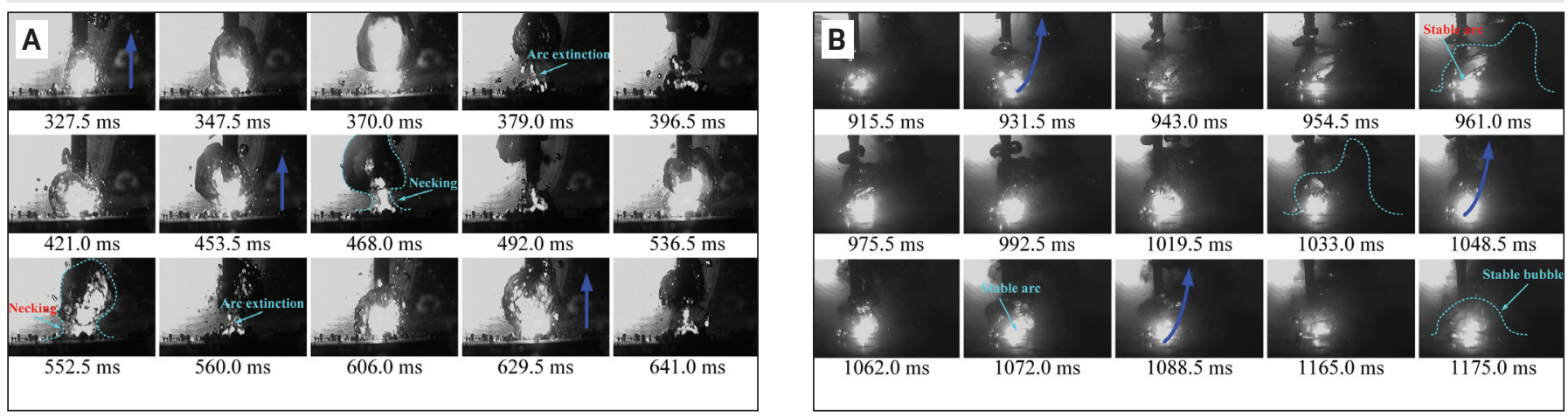

Fig. 10 - The captured bubble dynamic images at Group 4: A - Test Case 7, UWW; B - Test Case 8, U-UWW.

deformation of the gas bubble. When the gas bubble migrated downward to the workpiece surface, it was elongated along its radial direction and a bell-shaped construction was observed between the workpiece surface and the tube tip, as shown in Fig. 3C. Also, the bubble evolution cycle lasted about three times that without the ultrasonic wave.

The difference in the bubble motion process could be explained by the acoustic radiation force. Compared with the gas bubble rising upward in water due to the buoyant force, the gas bubble subjected to the ultrasonic wave started to migrate downward because initially the radiation force was greater than the buoyant force. This analysis was in accordance with the experimental observation, as shown in Fig. 3. The gas bubble motion process bears a resemblance to the dynamic process of the arc bubble generated by UWW to some degree. The experimental results may help to verify the feasibility of the proposed method that applied ultrasonic waves to control the arc bubble. It should be noted that a complex welding environment will have a significant effect on the physical properties inside the bubble, but the properties outside the bubble will be less affected. Thus, the effect of ultrasonic waves on the bubble should change little in nature even though the welding environment exists.

\section{Bubble Dynamics and Electrical Signal}

A series of welding experiments with wide ranges of welding current and arc voltage were carried out to investigate the bubble dynamics in UWW. Observations and analysis indicated that under different combinations of welding current and arc voltage, four fundamental bubble evolution modes could be detected in UWW by the authors (Ref. 13). Based on these four modes, this study will specifically discuss how ultrasonic wave changes their corresponding dynamic processes by the high-speed imaging system. Five group experiments were presented with welding current and arc voltage waveforms in UWW and U-UWW. The waveforms were used to predict the variation of the bubble dynamic feature.

\section{Test Cases 1 and $2\{7.5 \mathrm{~m} / \mathrm{min}, 20 \mathrm{~V}\}$}

In Group 1, Test Cases 1 and 2, the wire feed speed was $7.5 \mathrm{~m} / \mathrm{min}$ and the arc voltage was $20 \mathrm{~V}$. The only difference between the two test cases was whether the ultrasonic wave was exerted or not. Figure 4 shows the captured bubble dynamic images for Test Cases 1 and 2. Under the same welding conditions, even though the bubble evolved organically in the growing stage, the bubble burst always occurred in conventional UWW without the action of the ultrasonic wave, as shown in Fig. 4A. Some small, burst bubbles were dispersed in the vicinity. As a result, arc extinguishing was easily observed. As shown in Fig. 5A, the arc voltage rose to a maximum and remained for a period of time, whereas the welding current dropped to a minimum, accordingly.

When the ultrasonic wave was exerted, the bubble motion process was significantly changed so that an obliquely upward 
A
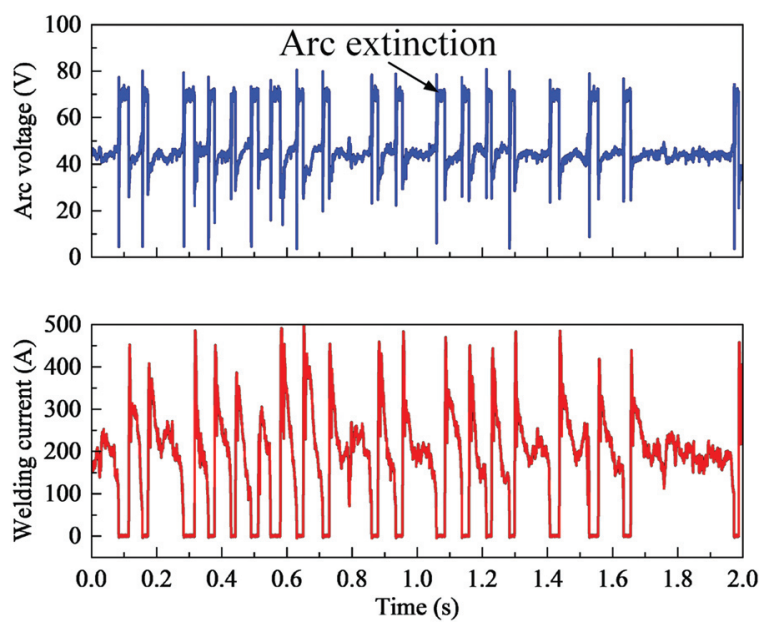

B
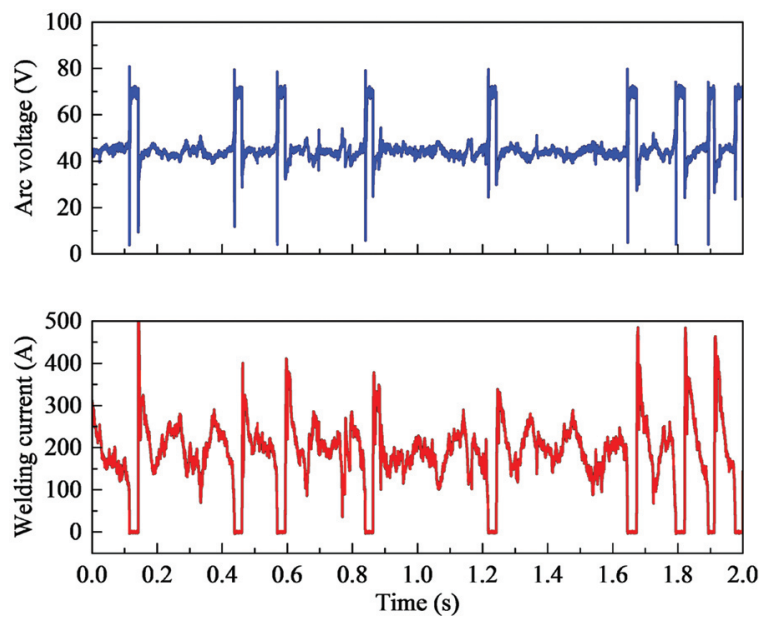

Fig. 11 - Arc voltage and welding current waveforms with time at Group 4: A - Test Case 7, UWW; B - Test Case 8, U-UWW.

trajectory was found, as shown in Fig. 4B. This means that the interaction of the ultrasonic wave with the arc bubble can change the bubble motion feature under the same welding conditions. In U-UWW, a deflected bubble was established first at instant $t=1082.0 \mathrm{~ms}$, and then it began to detach from the arc burning zone until the moment $t=1118.0 \mathrm{~ms}$. When the bubble burst appeared, ultrasonic waves exerted no noticeable effect on the arc bubble from 1152.5 to $1223.0 \mathrm{~ms}$.

In conventional UWW, on one hand, the lower arc voltage can lead to smaller bubble formation; on the other hand, it can also make the wire access the weld pool easier, resulting in short circuiting. Even if the bubble evolution process is affected by the ultrasonic wave in the growing stage, an undersized bubble plus an unstable welding arc cannot provide a relatively stable environment for U-UWW. In this case, bubble burst is still observed in U-UWW due to improper welding conditions. Again, arc extinguishing is produced in conjunction with undulate electrical signals, as shown in Fig. 5B. Hence, the arc extinguishing existing at lower voltage cannot be eliminated by the exertion of the ultrasonic wave, even though it changes the bubble dynamic process for Group 1.

\section{Test Cases 3 and $4\{6.0 \mathrm{~m} / \mathrm{min}, 28 \mathrm{~V}\}$}

As previously mentioned, improper welding parameters can interfere with the stability and integrity of the arc bubble, which, in turn, limits the effective impact of the ultrasonic wave on the arc bubble. Hence, the existence of a complete bubble is a prerequisite for ultrasonic application. To validate this point, in Group 2, Test Cases 3 and 4 were made with a wire feed speed of $6.0 \mathrm{~m} / \mathrm{min}$ and an arc voltage of $28 \mathrm{~V}$.

As shown in Fig. 6A, in conventional UWW, a growing bubble was established first in the weld pool surface at instant $t=$ $394.5 \mathrm{~ms}$, and its dimension was expanded until the moment $t=406.5 \mathrm{~ms}$. Then, from $t=425.5 \mathrm{~ms}$, the shape of the bubble was elongated along the axial direction, forming a necking at its bottom. Additionally, the bubble could not be maintained continuously, but periodically detached from the welding zone because it was dynamically fluctuated with time.

However, in U-UWW, a large bubble protecting the welding zone from water invasion was observed in Fig. 6B. As more gases inside the bubble were generated during welding, the bubble was extended along the radial direction rather than along the axial direction due to the ultrasonic wave. When extended to a certain extent, part of the bubble got rid of this entirely and was detached from the lateral side at instant $t=44.0$ $\mathrm{ms}$. In addition, a growing bubble was not only first established at the welding zone, but it could also be maintained continuously in the weld pool surface once the ultrasonic wave was exerted, as shown in Fig. 6B.

It should be noted that the periodically upward motion of the bubble tends to give the welding arc a shock, affecting the process stability (Ref. 13). Through analyzing the welding electrical signals in Fig. 7, the exertion of the ultrasonic wave made the fluctuation of electrical signals be reduced under the same welding conditions. This fact indicates that the interaction of the ultrasonic wave with the arc bubble can make the latter maintain a structural integrity around the welding zone, and the stable arc burning process is guaranteed.

\section{Test Cases 5 and $6\{9.0 \mathrm{~m} / \mathrm{min}, 32 \mathrm{~V}\}$}

With slightly higher values of both wire feed speed and arc voltage, in Group 3, Test Cases 5 and 6 were carried out to further check out the effectiveness of the ultrasonic wave in changing the bubble dynamic feature. As shown in Fig. $8 \mathrm{~A}$, the bubble grew dynamically and remained at the weld pool surface for a while until the moment $t=688.5 \mathrm{~ms}$, similarly to Test Case 3 . Then, a necking still emerged at the bubble bottom at $t=710.5 \mathrm{~ms}$. Further, at $t=730.0 \mathrm{~ms}$, a newly formed bubble merged with the previously detached bubble to form a community protecting the arc burning zone. As a result, a relatively stable protection effect could be obtained under the combined action of the two bubbles in conventional UWW.

When the ultrasonic wave was utilized, the bubble coalescence was not observed. No necking was present adjacent to the bubble bottom, and the bubble did not rise vertically but from the lateral side. As shown in Fig. 8B, a large bubble was continuously maintained in the weld pool surface in UUWW. Neither large bubble oscillation nor arc extinguishing was observed in the arc burning zone. 


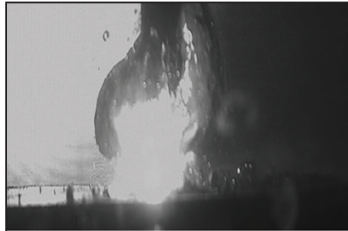

$200.0 \mathrm{~ms}$

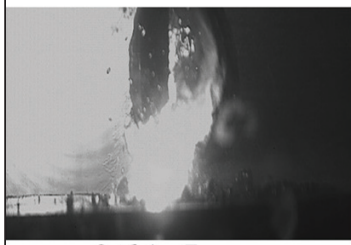

$361.5 \mathrm{~ms}$

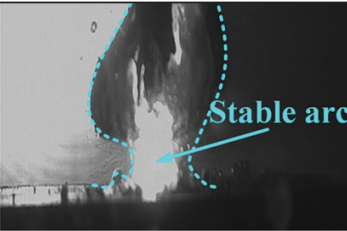

$216.0 \mathrm{~ms}$

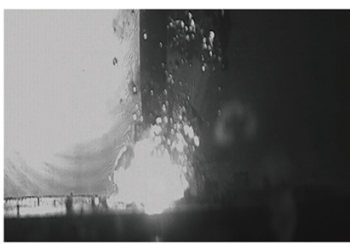

$387.5 \mathrm{~ms}$

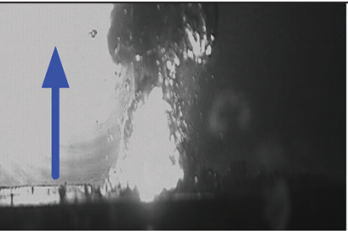

$234.5 \mathrm{~ms}$

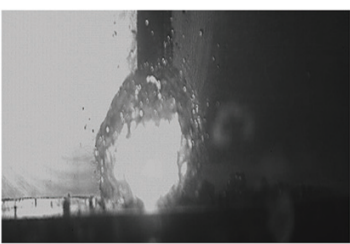

$415.0 \mathrm{~ms}$

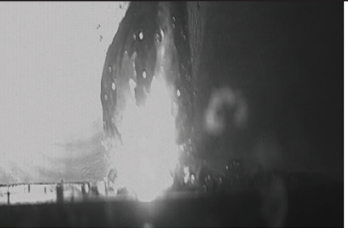

$283.5 \mathrm{~ms}$

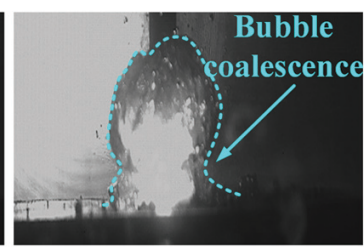

$430.5 \mathrm{~ms}$

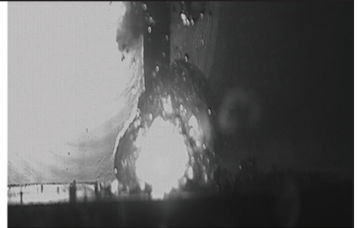

$317.5 \mathrm{~ms}$

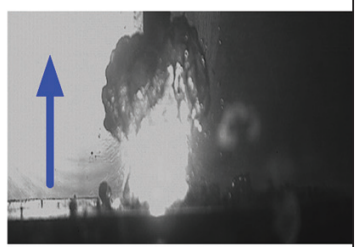

$447.0 \mathrm{~ms}$

Fig. 12 - The captured bubble dynamic images in UWW (Test Case 9)
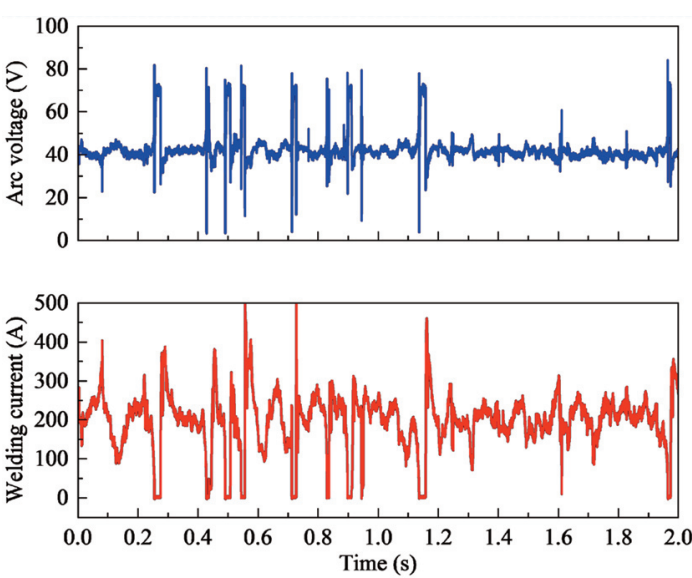

Fig. 13 - Arc voltage and welding current waveforms with time in UWW (Test Case 9).

Although the arc burning process was surrounded by a relatively stable bubble in conventional UWW, the bubble was not continuously maintained in the weld pool surface because it still rose periodically in a vertically upward direction. By comparing the welding electrical signals in Fig. 9, the fluctuation with very small amplitude was noticed in UUWW. It is clear that the variation in the bubble dynamic process by ultrasonic waves can further reduce the fluctuation of welding electric signals even if a relatively stable bubble state has been achieved in conventional UWW.

\section{Test Cases 7 and $8\{7.5$ m/min, 40 V\}}

If a larger arc voltage was used, an oversized bubble could be formed in conventional UWW. In Group 4, Test Cases 7 and 8 were performed in which the wire feed speed was 7.5 $\mathrm{m} / \mathrm{min}$ and the arc voltage was $40 \mathrm{~V}$.

As shown in Fig. 10A, the growing bubble remained invariably at the weld pool surface from 327.5 to $347.5 \mathrm{~ms}$. When the bubble grew to a maximum value, it began to rise vertically with a necking at its bottom at $t=370.0 \mathrm{~ms}$. At this time, the rising bubble would have a strong impact on welding arc, causing the latter to be extinguished. Successive arc extinguishing always occurred in conventional UWW at $t=379.0$, 492.0, 560.0, and $641.0 \mathrm{~ms}$. Under these welding conditions, as shown in Fig. 11A, welding current and arc voltage waveforms presented considerable fluctuation because the interference of the oversized bubble to the welding arc reached the extreme value when rising or oscillating.

Test Case 7 also indicated that the adverse effect of the bubble on arc behavior could be visualized by capturing dynamic images in which arc extinguishing was clearly visible. Compared with conventional UWW, the perturbation from the surrounding bubble was decreased in U-UWW, and the bubble shape and its dynamics were relatively stable, enabling it to better decouple with the welding arc and mitigating the impact of the unstabe bubble driven by water.

Furthermore, in U-UWW, the ultrasonic control of the bubble was weakened due to a larger buoyant force as a result of the oversized bubble. In this case, the detached bubble rose with a slight deflection but not vertically. However, the remanent bubble was always large enough to be maintained in the weld pool surface throughout the welding process. By observing the welding electrical signals in Fig. 11 , the changed bubble dynamic process by ultrasonic waves could reduce the frequency of arc extinguishing and the resulting fluctuation of welding electric signals under the circumstance of the oversized bubble.

\section{Test Case $9\{9.0 \mathrm{~m} / \mathrm{min}, 38 \mathrm{~V}\}$}

According to Test Case 7, the dynamic perturbation of the oversized bubble is one of the reasons for the appearance of successive arc extinguishing. This also indicates that the arc stiffness is low due to the large arc voltage, and it is difficult to resist this adverse effect. Therefore, we guess that if the arc stiffness is increased by changing welding parameters to resist the oversized bubble interference, is it possible to obtain a stable arc behavior? To validate this point, in Group 5, Test Case 9 was conducted with a higher wire feed speed of $9.0 \mathrm{~m} / \mathrm{min}$ and smaller arc voltage of $38 \mathrm{~V}$ in conventional UWW.

As shown in Fig. 12, the oversized bubble was still produced at the welding zone, but arc extinguishing was not observed when bubble rising at $t=216.0 \mathrm{~ms}$. This indicated that the greater arc stiffness produced by changing welding parameters could resist the strong impact of the oversized 
A
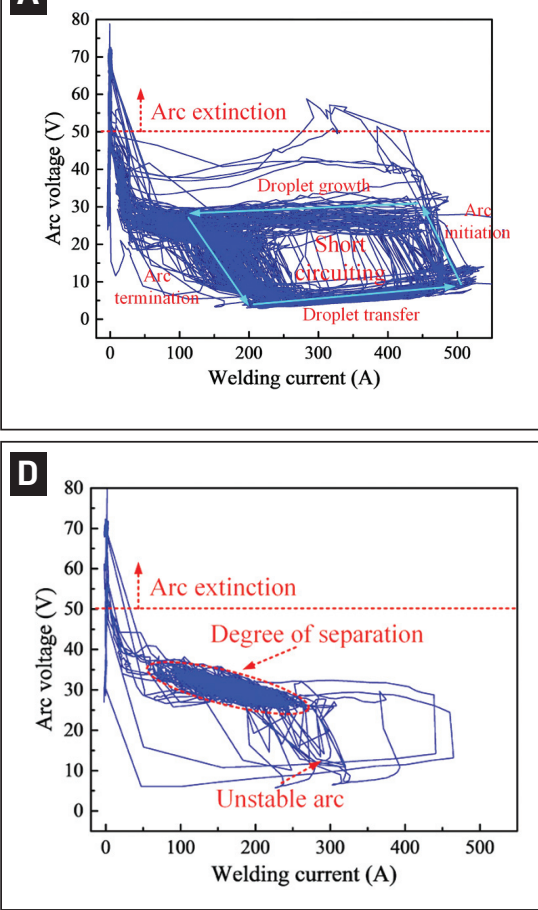

G

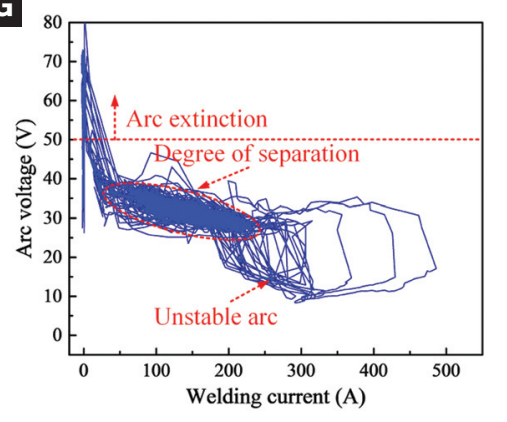

B

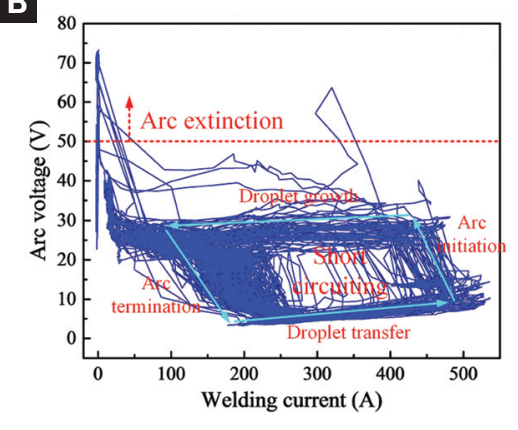

E

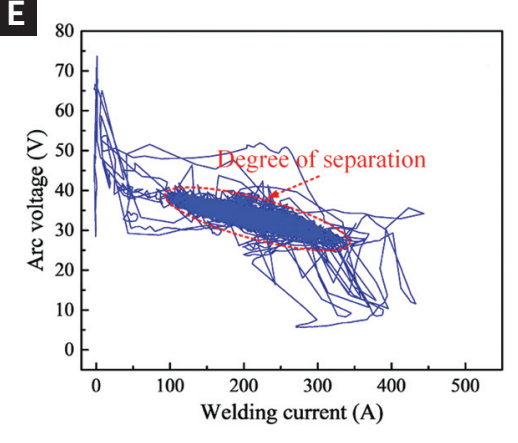

H

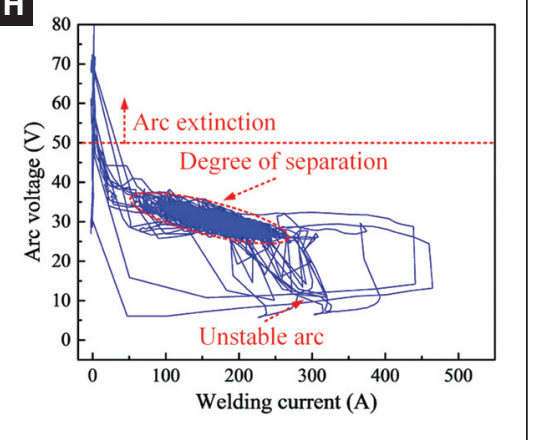

C
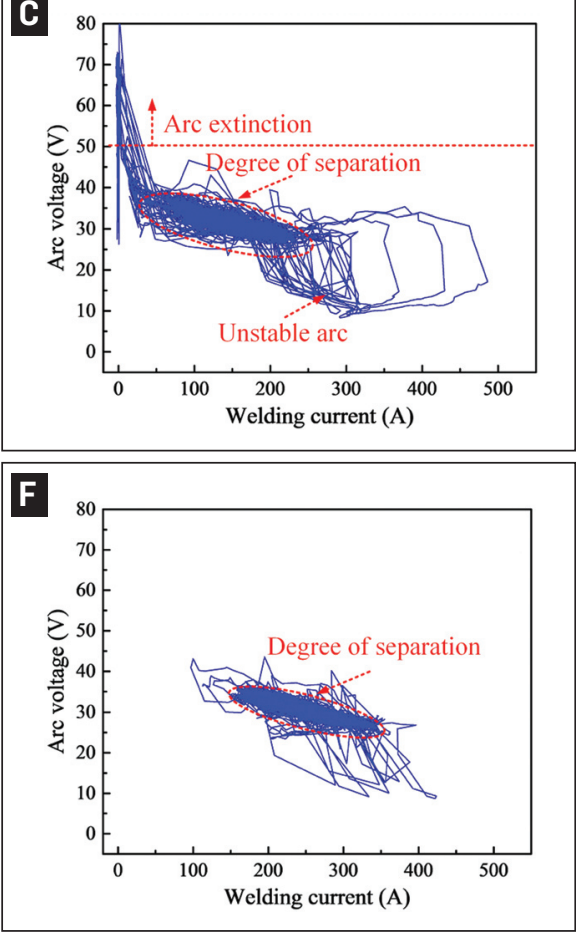

Fig. 14 - Arc voltage and welding current cyclograms in UWW and U-UWW: A Test Case 1, UWW; B - Test Case 2, UUWW; C - Test Case 3, UWW; D - Test Case 4, U-UWW; E - Test Case 5, UWW; F - Test Case 6, U-UWW; G - Test Case 7, UWW; H-Test Case 8, U-UWW.

burns stably. Further, the influence degree of ultrasonic control of the bubble in the four experimental groups was evaluated by process stability in the following section. bubble to some degree. However, by observing welding electrical signals in Fig. 13, the waveform of arc voltage occasionally rose to a higher value and then stayed for a while, indicating the occurrence of arc interruption. It can be concluded that although the welding arc is not extinguished when the bubble is rising, arc interruption may occur at other stages of the bubble evolution process because the dynamic interference of the bubble always exists throughout the welding process.

The changed welding parameters can affect the dynamic behavior of the bubble to a certain extent, and finally obtain a comparable welding process. However, this degree of influence is relatively small because the complex, unstable bubble dynamics affects the welding process all the time. Thus, the active control of the bubble by external method is the most fundamental point for overcoming this drawback in conventional UWW.

The ultrasonic wave assisted in the UWW process provides a promising approach. The ultrasonic control of the bubble can change the bubble dynamic process and enable the large bubble attached to the weld pool surface for a long time. On the other hand, the adverse effect of the dynamic rising of the bubble is weakened so that the welding arc

\section{Process Stability Evaluation}

As previously mentioned, if the bubble perturbation caused by water is reduced, the stability of the welding process must be enhanced in the U-UWW process. To examine this point, experiments were carried out by evaluating the voltage and current (U-I) cyclograms as well as the variation coefficients of voltage and current.

Figure 14 shows the U-I cyclograms in conventional UWW and U-UWW. Under the conditions of Test Cases 1 and 2, the U-I cyclograms were both loop-locked quadrilaterals, as shown in Fig. 14A and B. They were typical symbols of the short-circuiting process. In a single loop-locked quadrilateral, the four phases (i.e., droplet growth, arc termination, droplet transfer, and arc initiation) revealed the different processes during a complete short-circuiting process. In addition, many abnormal lines appeared in the upper-left corner, indicating the occurrence of arc extinguishing. This was caused by the bubble burst at a lower arc voltage. Comparing Fig. 14A and $\mathrm{B}$, the abnormal lines were reduced to some degree in U-UWW.

By observing Test Cases 3-8, the loop-locked quadrilater- 

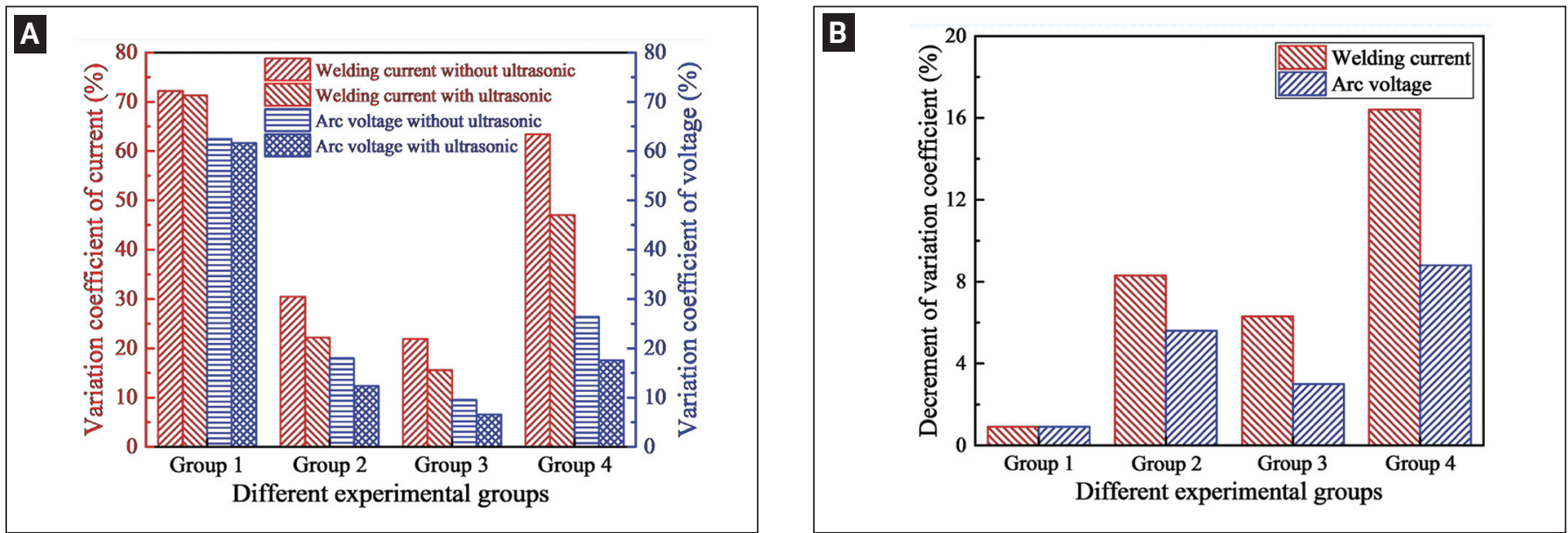

Fig. 15 - Process stability indexes evaluation in UWW and U-UWW: A - Coefficients of variation of arc voltage and welding current; $B$ - decrement of variation coefficients after the exertion of the ultrasonic wave.

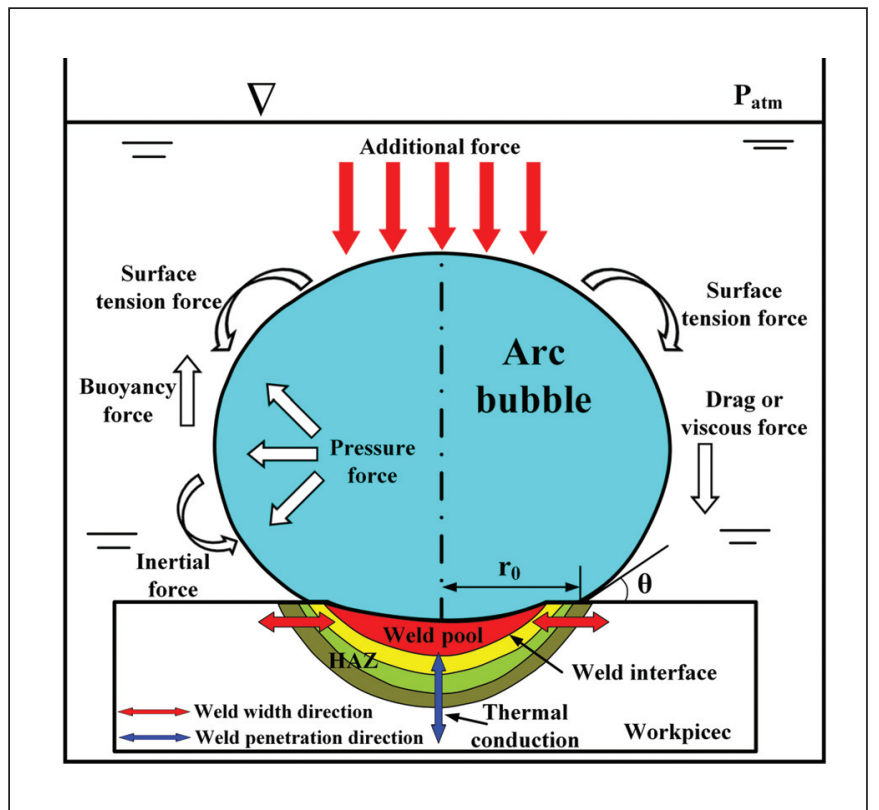

Fig. 16 - Analysis of the forces acting on the arc bubble in $U-$ UWW.

al characteristics disappeared and the dynamic movement of the working point was concentrated in a certain area. As shown in Fig. 14C, E, and G, no obvious signs of the shortcircuiting process could be observed, whereas the arc extinguishing process appeared invariably and accounted for a large proportion in conventional UWW.

Under the same welding conditions with the ultrasonic wave, the degree of the separation of the working point was reduced and the clusters of the U-I cyclograms were concentrated, as shown in Fig. 14D, F, and H. The arc burning process was strengthened, and a few signs of the arc extinguishing process were observed when the ultrasonic wave was exerted. Especially, there was no arc extinguishing process existing in U-UWW for Test Case 6. In one word, the process stability of U-UWW presented much better properties than that of conventional UWW for the four experimental groups.

To quantitatively evaluate the process stability, the varia- tion coefficients of welding current and arc voltage were calculated in conventional UWW and U-UWW. As shown in Fig. $15 \mathrm{~A}$, with varying the experimental group, the variation coefficients showed a significant difference. Whether the ultrasonic wave was exerted or not, the variation coefficients of current and voltage both followed the order Group $1>$ Group 4 > Group 2 > Group 3. Further, under the same welding conditions, the variation coefficient of the current was much larger than that of the voltage in conventional UWW and U-UWW because a constant-voltage mode of the welding power source was used.

In addition, under the same experimental group, the variation coefficients of current and voltage with the ultrasonic wave both yielded significantly smaller values than those without the ultrasonic wave. Whether analyzing the current or voltage variation coefficient, a minimum value was observed at Group 3 in conventional UWW and UUWW. In fact, the process stability can be quantitatively evaluated by the variation coefficient. The higher the variation coefficient, the more unstable the welding process, and vice versa (Ref. 44). This indicated the enhanced process stability in U-UWW for all the experimental groups.

After exerting the ultrasonic wave in UWW, the decrement of variation coefficient, including welding current and arc voltage, is shown in Fig. 15B. For the variation coefficient, the difference between UWW and U-UWW became very significant with varying the experimental group, the maximum difference of which occurred at Group 4. When Group 1 was compared, the variation coefficient of the current was about $72.2 \%$ and $71.3 \%$ for UWW and U-UWW, respectively, and the exertion of the ultrasonic wave only made it decrease by $0.9 \%$. When Group 4 was compared, the variation coefficient of current was about $63.4 \%$ and $47.0 \%$ for UWW and U-UWW, respectively, and the exertion of the ultrasonic wave made it decrease by $16.4 \%$.

It is observed from these results that the addition of ultrasonic waves in UWW indicates an improvement in the process stability. Due to varying welding parameters (i.e., different experimental groups), the effect of ultrasonic waves on process stability makes a significant difference, which is in accordance with the influence degree of ultrasonic control of the bubble. 


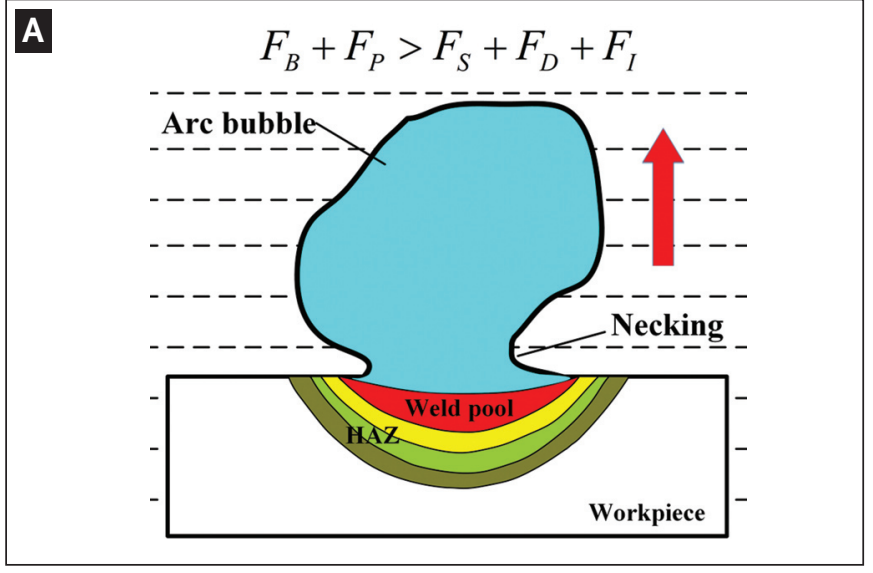

C

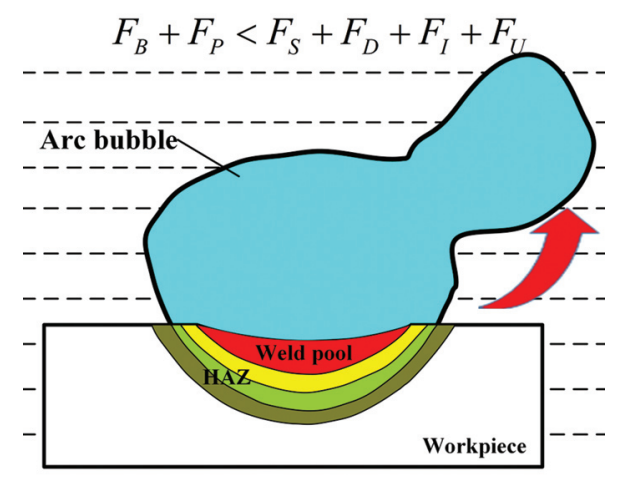

B

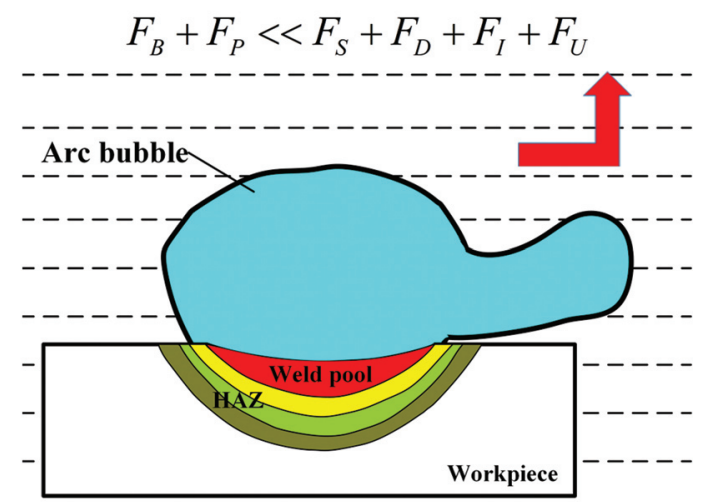

D

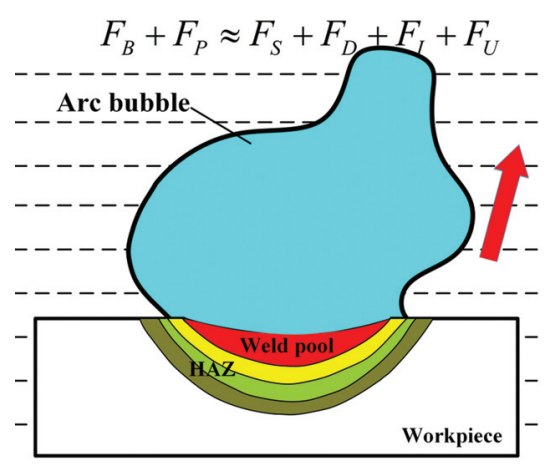

Fig. 17 - Comparison of the simplified bubble motion: A - Test Case 3, UWW; B - Test Case 4, U-UWW; C - Test Case 6, U-UWW; D-Test Case 8, U-UWW.

\section{Analysis and Discussion}

The experimental results in Figs. 14 and 15 demonstrated that U-UWW could achieve an increase in maintaining the process stability under the same welding conditions. This further confirmed the effectiveness of the ultrasonic control of the bubble for mitigating the adverse effect of the dynamic rising of the bubble. The underlying mechanism may be elucidated as follows. During wet welding, the fluxcored wire is decomposed and the water is ionized or vaporized, together forming an effective protection space. The bubble emerges and is attached to the weld pool surface. Hence, the arc behavior, metal transfer process, and hightemperature weld pool solidification proceed in the bubble cavity. Due to the interaction between the water environment and the bubble, the bubble presents periodical motion. The bubble grows at the weld pool surface, then rises vertically and finally detaches, repeatedly.

The bubble evolution process is governed by a combination of forces acting on the bubble. The interplay of these forces dictates the bubble dynamics, such as bubble growth time and detachment volume, etc. In conventional UWW, there are five different forces that are usually considered: buoyant force $\left(F_{B}\right.$, upward), contact pressure force due to the overpressure inside the bubble ( $F_{P}$, upward), surface tension force due to capillary action $\left(F_{S}\right.$, downward), drag force due to moving liquid ( $F_{D}$, downward), and inertial force ( $F_{I}$, downward).

During the bubble growth process, under quasi-static force balance conditions, the buoyant force and the contact pressure force promote the bubble detachment, whereas the surface tension force, drag force, and inertial force resist the bubble detachment and keep the bubble attached to the weld pool surface, as schematically depicted in Fig. 16. Once the detaching forces exceed the retaining forces, the bubble always forms a necking at its lower part and is then lifted away from the weld pool surface. Finally, the bubble moves in a vertical direction. After the bubble detachment, only the buoyant force, drag force, and inertial force play a role.

When the ultrasonic wave is applied to the UWW process, the bubble is exerted an additional force so that its dynamics start to change, as shown in Fig. 16. The additional force is the acoustic radiation force $\left(F_{U}\right.$, downward) induced by the acoustic wave and even the ultrasound (Ref. 41). Essentially, the acoustic radiation force is originated from the acoustic pressure difference along the bubble surface, and it is defined as

$$
F_{U}=\frac{2 \alpha}{\rho_{l} c_{l}^{2}}|P|^{2}
$$

(Ref. 45) where $\alpha$ is the acoustic absorption coefficient of 15 $\mathrm{kHz}$ in water, $\rho_{l}$ is the density of water, $c_{l}$ is the velocity of ultrasound propagation in water, and $P=P_{A} \cos (\omega t)$ is the acoustic pressure $\left(P_{A}\right.$ is the maximum acoustic pressure and $\omega$ is the angular frequency).

The addition of $F_{U}$ constitutes a new quasi-static force 

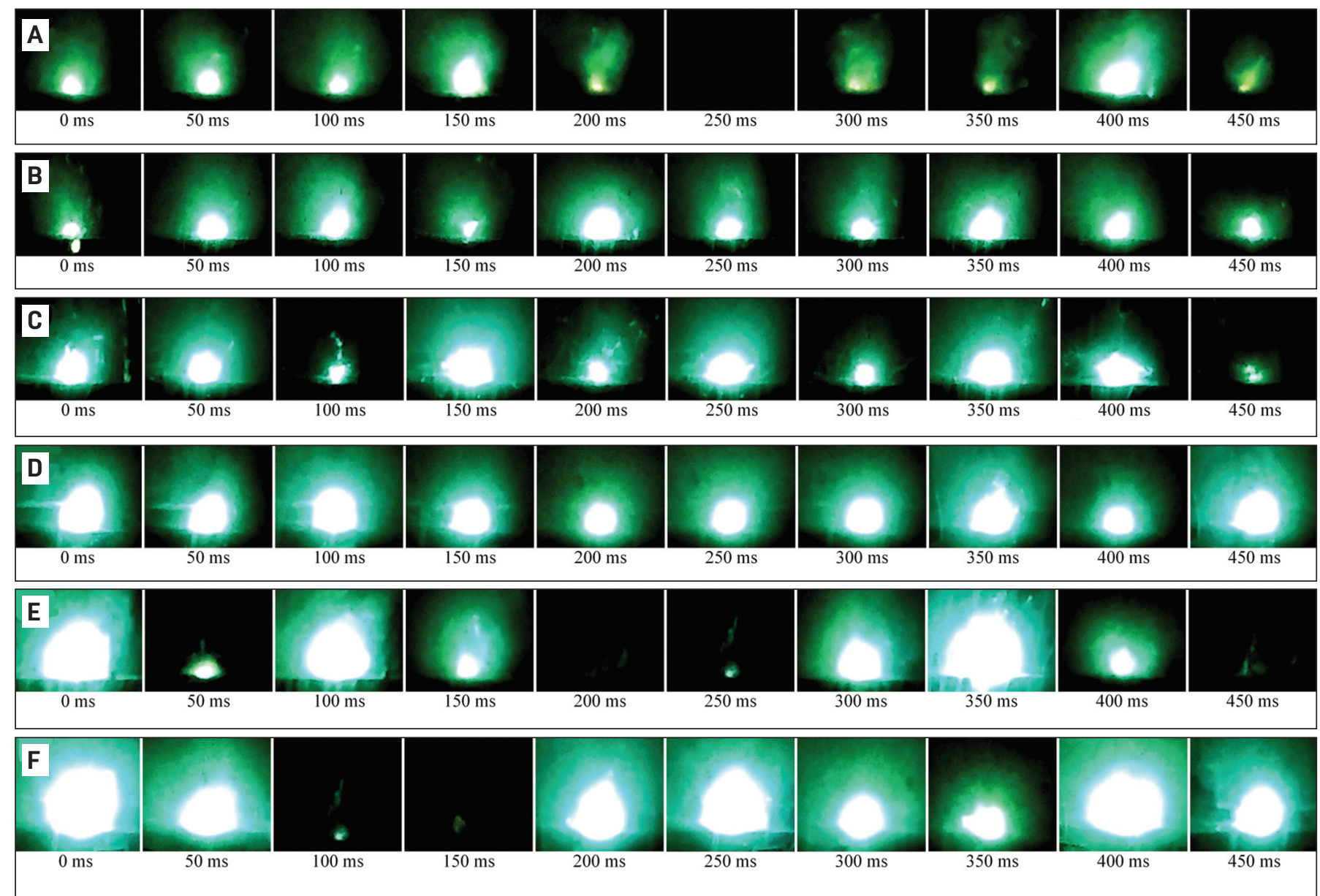

Fig. 18 - Dynamic behavior of the arc burning process in UWW and U-UWW: A - Test Case 3, UWW; B - Test Case 4, U-UWW; C Test Case 5, UWW; D - Test Case 6, U-UWW; E - Test Case 7, UWW; F - Test Case 8, U-UWW.

balance condition in U-UWW, which can take the form of $F_{B}+F_{P}+F_{S}+F_{D}+F_{I}+F_{U}$ during the bubble growth process. The downward-directed $F_{U}$ acts on the bubble. On one hand, it can cause a larger bubble steadily attached to the weld pool surface. The common necking phenomenon existing in conventional UWW has been eliminated. This indicates that the ultrasonic wave makes the expansion and contraction of the bubble with large amplitude produce a reduced trend.

On the other hand, as more gases are continuously generated inside the bubble, the bubble expands more along the radial direction rather than the axial direction so that its radial size increases. When expanded to maximum size, the bubble starts to rise up and is divided into two parts due to the perturbation of the welding torch as welding occurs and the internal properties of the bubble. A large part is still attached to the weld pool surface by ultrasonic wave. Meanwhile, the other part rises up from this position away from the arc burning zone. Hence, the addition of the ultrasonic wave causes the bubble motion with a certain angle with respect to the welding torch axis so that the welding process is not easily affected by the rising of lateral bubble.

For U-UWW, although the bubble can reach a good structural integrity with almost constant size attached to the welding pool surface, the degree of ultrasonic control of the bubble exhibits various features. Bubble volume has a significant effect on its motion with a certain angle with respect to the welding torch axis. Figure 17 shows a comparison of the simplified bubble motion in UWW and U-UWW. In fact, the buoyant force is directly proportional to bubble volume (Refs. 39, 40). For experimental Group 2, since the bubble volume is relatively small, the buoyant force is not so high and there is room for further control over the bubble by the ultrasonic wave. Hence, the trajectory of the bubble motion takes on a horizontal movement first and then rises, resembling a 90-deg transition, as compared in Fig. 17A and B. At the same time, it can be inferred that the retaining forces are much greater than the detaching forces throughout the welding process.

For experimental Group 3, as the bubble volume increases, the degree of ultrasonic control is decreased due to the increased buoyant force. The bubble moves in an obliquely upward direction, as shown in Fig. 17C. Even though the buoyant force increases, ultrasonic control of the bubble still has a significant effect, and an obvious difference in bubble motion between UWW and U-UWW is observed.

For experimental Group 4, with a further increase in bubble volume, the influence of buoyant force is enhanced and dominates. This large increase has the potential to push the bubble motion vertically upward. As a result, the additional room for control by the ultrasonic wave becomes less because the buoyant force is already large enough. This is the reason why the bubble with slight deflection is found when 
the larger bubble is exerted by ultrasonic wave, as shown in Fig. 17D.

Due to the interaction between the ultrasonic wave and the bubble in UWW, the above-mentioned acoustic radiation force can improve the bubble dynamic process, enabling the large bubble to surround the arc burning zone for a long time and changing the trajectory of the dynamic rising of the bubble. In particular, the relative contribution of the dynamic bubble with the vertically rising mode diminishes under the action of the ultrasonic wave. Thus, the adverse effect of the dynamic rising of the bubble is weakened, and the process stability is enhanced, as verified in Figs. 14 and 15.

To have a brief insight into the ultrasonic control of the bubble, high-speed imaging was also performed to observe the arc burning process inside the bubble, as shown in Fig. 18. In conventional UWW, since the welding arc with uneven size is intermittently extinguished and reignited, the arc burning process cannot be maintained at a stable state for Test Case 3 in Fig. 18A. The deterioration of the arc burning process is attributed to the dynamic bubble with vertically rising mode, which causes the arc an intense oscillation, adversely affecting the ability of the arc to burn continuously. A similar trend is also found in other test cases, but there is a stronger effect between the welding arc and dynamic bubble for Test Case 7 than for Test Cases 3 and 5 .

However, with the ultrasonic wave, the oscillation of the arc with a small amplitude is observed in U-UWW. The size of the arc does not vary significantly with time. When different test cases are used, the arc stability with ultrasonic waves are all significantly higher than that without ultrasonic waves. Especially for Test Case 6, the arc with few signs of oscillation is observed, verifying the better arc stability, as shown in Fig. 18D. Additionally, the bubble controlled by ultrasonic waves always maintains a stable state without significant oscillation, thus having a limited effect on the arc burning process. When conducted in U-UWW, a better arc burning process can be afforded, corresponding to an enhanced process stability.

\section{Conclusions}

The following may be concluded:

1) The bubble dynamic feature under an acoustic field was demonstrated and analyzed by visual sensing and welding electrical signals in U-UWW for the first time.

2) The ultrasonic wave can enable the large bubble attached to the arc burning zone for a long time, and the common necking phenomenon existing in conventional UWW has been eliminated.

3) Under the same welding conditions, the addition of ultrasonic waves can cause the bubble motion of a certain angle with respect to the welding torch axis so that the welding process is not easily affected by the rising of lateral bubble.

4) For all experimental groups, the variation coefficients of welding current and arc voltage with ultrasonic waves both yield significantly smaller values than those without ultrasonic waves, indicating better process stability in U-UWW.

5) The interaction of ultrasonic waves with the bubble can result in an enhanced arc burning process. The oscillation of the arc with a small amplitude is observed. However, the underlying mechanism needs further research.

\section{Acknowledgments}

The authors are grateful for the financial support from the National Natural Science Foundation of China (Grant No. 51475104, 51435004) and the National Key Research and Development Program of China (Grant No. 2016YFB0300602).

\section{References}

1. Perez-Guerrero, F., and Liu, S. 2005. Maintenance and repair welding in the open sea. Welding Journal 84(11): 54-s to 59-s.

2. Teng, J. H., Wang, D. P., Wang, Z. J., Zhang, X. D., Li, Y. H., Cao, J., Xu, W., and Yang, F. 2017. Repair of arc welded DH36 joint by underwater friction stitch welding. Materials and Design 118(15): 266-278. DOI: 10.1016/j.matdes.2017.01.016

3. Ghadimi, P., Ghassemi, H., Ghassabzadeh, M., and Kiaei, Z. 2013. Three-dimensional simulation of underwater welding and investigation of effective parameters. Welding Journal 92(8): 239-s to 249-s.

4. Jia, C. B., Zhang, T., Maksimov, S. Y., and Yuan, X. 2013. Spectroscopic analysis of the arc plasma of underwater wet fluxcored arc welding. Journal of Materials Processing Technology 213: 1370-1377. DOI: 10.1016/j.jmatprotec.2013.02.013

5. Jia, C. B., Zhang, Y., Zhao, B., Hu, J. K., and Wu, C. S. 2016 Visual sensing of the physical process during underwater wet FCAW. Welding Journal 95(6): 202-s to 209-s.

6. Keenan, P. J. 1993. Thermal insulation of wet shielded metal arc welds. Master thesis, Massachusetts Institute of Technology, Cambridge, Mass.

7. Guo, N., Fu, Y., Feng, J., Du, Y., Deng, Z., Wang, M., and Tang, D. 2016. Classification of metal transfer mode in underwater wet welding. Welding Journal 95(4): 133-s to 140-s.

8. Zhang, Y., Jia, C. B., Zhao, B., Hu, J. K., and Wu, C. S. 2016 Heat input and metal transfer influences on the weld geometry and microstructure during underwater wet FCAW. Journal of Materials Processing Technology 238: 373-382. DOI: 10.1016/j. jmatprotec.2016.07.024

9. Pessoa, E. C. P., Ribeiro, L. F., Bracarense, A. Q., Dias, W. C., Andrade, L. G. D., Liu, S., Santos, V. R., and Monteiro, M. J. 2010. Arc stability indexes evaluation on underwater wet welding. $29^{\text {th }} \mathrm{In}$ ternational Conference on Ocean, Offshore and Arctic Engineering, pp. 195-201. Shanghaim, China.

10. Tsai, C. L., and Masubuchi, K. 1979. Mechanisms of rapid cooling in underwater welding. Applied Ocean Research 1(2): 99110. DOI: 10.1016/0141-1187(79)90023-3

11. Guo, N., Guo, W., Du, Y., Fu, Y., and Feng, J. 2015. Effect of boric acid on metal transfer mode of underwater flux-cored wire wet welding. Journal of Materials Processing Technology 223: 124128. DOI: 10.1016/j.jmatprotec.2015.04.002

12. Oliveira, F. D. R., Soares, W. R., and Bracarense, A. Q. 2015. Study correlating the bubble phenomenon and electrical signals in underwater wet welding with covered electrodes. Welding International 29(5): 363-371. DOI: 10.1080/09507116.2014.932980

13. Feng, J. C., Wang, J. F., Sun, Q. J., Zhao, H. Y., Wu, L. J., and $\mathrm{Xu}, \mathrm{P}$. W. 2017. Investigation on dynamic behaviors of bubble evolution in underwater wet flux-cored arc welding. Journal of Manufacturing Processes 28: 156-167. DOI: 10.1016/j.jmapro.2017.06. 003

14. Guo, N., Du, Y. P., Feng, J. C., Guo, W., and Deng, Z. Q. 2015. Study of underwater wet welding stability using an x-ray transmission method. Journal of Materials Processing Technology 225: 133138. DOI: 10.1016/j.jmatprotec.2015.06.003

15. Świerczyńska, A., Fydrych, D., and Rogalski, G. 2017. Diffusible hydrogen management in underwater wet self-shielded flux 
cored arc welding. International Journal of Hydrogen Energy 42(38): 24532-24540. DOI: 10.1016/j.ijhydene.2017.07.225

16. Wang, J. F., Sun, Q. J., Wu, L. J., Liu, Y. B., Teng, J. B., and Feng, J. C. 2017. Effect of ultrasonic vibration on microstructural evolution and mechanical properties of underwater wet welding joint. Journal of Materials Processing Technology 246: 185-197. DOI: 10.1016/j.jmatprotec.2017.03.019

17. Arias, A. R., and Bracarense, A. Q. 2017. Fatigue crack growth assessment in underwater wet welds. Welding Journal 96(8): 287-s to 294-s.

18. Zhang, H. T., Dai, X. Y., Feng, J. C., and Hu, L. L. 2015. Preliminary investigation on real-time induction heating-assisted underwater wet welding. Welding Journal 94(1): 8-s to 15-s.

19. Tomków, J., Fydrych, D., Rogalski, G., and Łabanowski, J. 2018. Improvement of S355G10+N steel weldability in water environment by temper bead welding. Journal of Materials Processing Technology 262: 372-381. DOI: 10.1016/j.jmatprotec.2018.06.034

20. Guo, N., Xu, C. S., Guo, W., Du, Y. P., and Feng, J. C. 2015. Characterization of spatter in underwater wet welding by $\mathrm{x}$-ray transmission method. Materials and Design 85: 156-161. DOI: 10.1016/j.matdes.2015.06.152

21. Chen, H., Guo, N., Shi, X. H., Du, Y. P., Feng, J. C., and Wang, G. D. 2018. Effect of hydrostatic pressure on protective bubble characteristic and weld quality in underwater flux-cored wire wet welding. Journal of Materials Processing Technology 259: 159168. DOI: 10.1016/j.jmatprotec.2018.04.037

22. Chen, H., Guo, N., Shi, X. H., Du, Y. P., Feng, J. C., and Wang, G. D. 2018. Effect of water flow on the arc stability and metal transfer in underwater flux-cored wet welding. Journal of Manufacturing Processes 31: 103-115. DOI: 10.1016/j.jmapro.2017.11. 010

23. Wang, L., Xie, F., Feng, Y., and Wang, Z. 2017. Innovative methodology and database for underwater robot repair welding: A technical note. ISIJ International 57(203): 203-205. DOI: 10.2355/ isijinternational.ISIJINT-2016-407

24. Clukey, D. A. 1999. Evaluation and analysis of underwater wet welding process. Master thesis, The Ohio State University, Columbus, Ohio.

25. Wang, J. F., Sun, Q. J., Jiang, Y. L., Zhang, T., Ma, J. K., and Feng, J. C. 2018. Analysis and improvement of underwater wet welding process stability with static mechanical constraint support. Journal of Manufacturing Processes 34: 238-250. DOI: 10. 1016/j.jmapro.2018.06.007

26. Cunha, T. V., and Bohórquez, C. E. N. 2015. Ultrasound in arc welding: A review. Ultrasonics 56: 201-209. DOI: 10.1016/j. ultras.2014.10.007

27. Kumar, S., Wu, C. S., Padhy, G. K., and Ding, W. 2017. Application of ultrasonic vibrations in welding and metal processing: A status review. Journal of Manufacturing Processes 26: 295-322. DOI: 10.1016/j.jmapro.2017.02.027

28. Sun, Q. J., Lin, S. B., Yang, C. L., and Zhao, G. Q. 2009. Penetration increase of AISI304 using ultrasonic assisted tungsten inert gas welding. Science and Technology of Welding and Joining 14(8): 765-767. DOI: $10.1179 / 136217109 X 12505932584772$

29. Wang, J. F., Sun, Q. J., Liu, J. P., Wang, B., and Feng, J. C. 2017. Effect of pulsed ultrasonic on arc acoustic binding in pulsed ultrasonic wave-assisted pulsed gas tungsten arc welding. Science and Technology of Welding and Joining 22(6): 465-471. DOI: 10. 1080/13621718.2016.1258812

30. Xie, W. F., Fan, C. L., Yang, C. L., and Lin, S. B. 2018. Experimental investigation on acoustic control droplet transfer in ultrasonic-wave-assisted gas metal arc welding. Metallurgical and Materials Transactions B 49(1): 274-281. DOI: 10.1007/s11663-0171146-y

31. Xie, W. F., Fan, C. L., Yang, C. L., and Lin, S. B. 2016. Effect of acoustic field parameters on arc acoustic binding during ultrasonic wave-assisted arc welding. Ultrasonics Sonochemistry 29: 476-
484. DOI: 10.1016/j.ultsonch.2015.11.001

32. Fan, C. L., Yang, C. L., Lin, S. B., and Fan, Y. Y. 2013. Arc characteristics of ultrasonic wave-assisted GMAW. Welding Journal 92(12): 375-s to 380-s.

33. Fan, Y. Y., Yang, C. L., Lin, S. B., Fan, C. L., and Liu, W. G. 2012. Ultrasonic wave assisted GMAW. Welding Journal 91(3): 91-s to 99 -s.

34. Wu, C. S., Zhao, C. Y., Zhang, C., and Li, Y. F. 2017. Ultrasonic vibration-assisted keyholing plasma arc welding. Welding Journal 96(8): 279-s to 286-s.

35. Wang, J. F., Sun, Q. J., Teng, J. B., Jin, P., Zhang, T., and Feng, J. C. 2018. Enhanced arc-acoustic interaction by steppedplate radiator in ultrasonic wave-assisted GTAW. Journal of Materials Processing Technology 262: 19-31. DOI: 10.1016/j.jmatprotec. 2018.06.025

36. Xie, W. J., and Wei, B. 2003. Temperature dependence of single-axis acoustic levitation. Journal of Applied Physics 93(5): 3016-3021. DOI: 10.1063/1.1540232

37. Wang, J. F., Sun, Q. J., Zhang, S., Wang, C. J., Wu, L. J., and Feng, J. C. 2018. Characterization of the underwater welding arc bubble through a visual sensing method. Journal of Materials Processing Technology 251: 95-108. DOI: 10.1016/j.jmatprotec.2017. 08.019

38. Sun, Q. J., Cheng, W. Q., Liu, Y. B., Wang, J. F., Cai, C. W., and Feng, J. C. 2016. Microstructure and mechanical properties of ultrasonic assisted underwater wet welding joints. Materials and Design 103: 63-70. DOI: 10.1016/j.matdes.2016.04.019

39. Vafaei, S., Angeli, P., and Wen, D. S. 2011. Bubble growth rate from stainless steel substrate and needle nozzles. Colloids and Surfaces A 384: 240-247. DOI: 10.1016/j.colsurfa.2011.03.066

40. Bari, S. D., and Robinson, A. J. 2013. Experimental study of gas injected bubble growth from submerged orifices. Experimental Thermal and Fluid Science 44(1): 124-137. DOI: 10.1016/j. expthermflusci.2012.06.005

41. Ma, X., Xing, T., Huang, B., Li, Q., and Yang, Y. 2018. Combined experimental and theoretical investigation of the gas bubble motion in an acoustic field. Ultrasonics Sonochemistry 40: 480-487. DOI: 10.1016/j.ultsonch.2017.07.035

42. Abe, Y., Kawaji, M., and Watanabe, T. 2002. Study on the bubble motion control by ultrasonic wave. Experimental Thermal and Fluid Science 26(6): 817-826. DOI: 10.1016/S0894-1777(02) 00197-8

43. Nomura, S., and Nishida, K. 2003. Numerical simulation of a single bubble rising in an ultrasonic standing wave field. Japanese Journal of Applied Physics 42(5B): 2975-2980. DOI: 10.1143/JJAP. 42.2975

44. Li, H. L., Liu, D., Guo, N., Chen, H., Du, Y. P., and Feng, J. C. 2017. The effect of alumino-thermic addition on underwater wet welding process stability. Journal of Materials Processing Technology 245: 149-156. DOI: 10.1016/j.jmatprotec.2017.02.023

45. Wu, W. H., Zhai, W., Hu, H. B., and Wei, B. B. 2017. Acoustic field and convection pattern within liquid material during ultrasonic processing. Acta Physica Sinica 66(19): 194303. DOI: 10.7498/aps.66.194303

JIANFENG WANG, QINGJIE SUN (qjsun@hit.edu.cn), and JICAI FENG are with the State Key Laboratory of Advanced Welding and Joining, Harbin Institute of Technology, Harbin, China. JUNBO TENG, WANG, SUN, and FENG are with the Shandong Provincial Key Laboratory of Special Welding Technology, Harbin Institute of Technology at Weihai, China. 